Review

\title{
The Role of the Slit/Robo Signaling Pathway
}

\author{
Mingfu Tong ${ }^{1,2}$, Tie Jun ${ }^{\circledR}$, Yongzhan $\mathrm{Nie}^{2}$, Jianyu Hao ${ }^{1 凶}$, Daiming Fan ${ }^{2 \bowtie}$ \\ 1. Department of Gastroenterology, Beijing Chao-Yang Hospital, Capital Medical University, Beijing 100020, China. \\ 2. State Key Laboratory of Cancer Biology and Xijing Hospital of Digestive Diseases, Xijing Hospital, Fourth Military Medical University, Xi'an 710032, China. \\ $\bowtie$ Corresponding authors: Daiming Fan, email: daimingfan@fmmu.edu.cn; phone number: +86-029-84775507; Jun Tie, email: tiejun7776@163.com; Jianyu Hao, \\ email: haojianyu@ccmu.edu.cn \\ (C) Ivyspring International Publisher. This is an open access article distributed under the terms of the Creative Commons Attribution (CC BY-NC) license \\ (https://creativecommons.org/licenses/by-nc/4.0/). See http://ivyspring.com/terms for full terms and conditions.
}

Received: 2018.11.29; Accepted: 2019.04.28; Published: 2019.06.02

\begin{abstract}
The Slit family is a family of secreted proteins that play important roles in various physiologic and pathologic activities via interacting with Robo receptors. Slit/Robo signaling was first identified in the nervous system, where it functions in neuronal axon guidance; nevertheless, an increasing number of studies have shown that Slit/Robo signaling even regulates other activities, such as angiogenesis, inflammatory cell chemotaxis, tumor cell migration and metastasis. Although the precise role of the ligand-receptor in organisms has been obscure and the conclusions drawn are sometimes paradoxical, tremendous advances in understanding the Slit/Robo signaling pathway have been made. As such, our review summarizes the characteristics of the Slit/Robo signaling pathway and its role in various cell types.
\end{abstract}

Key words: Slit, Robo, neuro, angiogenesis, chemotaxis, cancer, motility

\section{Introduction}

Slits are highly conserved secreted glycoproteins that regulate many physiologic processes, such as neuronal axon guidance, cell proliferation, cell migration, and vascularization, via binding to Robo receptors [1]. Slit/Robo signaling was originally recognized by humans as attracting and repelling neuron axons to across the midline [2]. Since then, the Slit/Robo signaling pathway has also been found to play an important role in the development of organs, such as diaphragm, kidney, heart and mammary gland, in addition to the nervous system [3-6]. More recently, accumulating studies reported that Slit/Robo signaling was altered in various cell types and proved that it acts as a vital regulator in keeping physical or pathological function. Herein, we summarize advances in Slit/Robo signaling in various functional events.

\section{Characteristics of Slit and Robo}

\section{Structural characteristics of Slit protein}

Slit proteins are a class of single peptides with approximately 1500 amino acids. Invertebrates have only one Slit, while vertebrates have Slit1, Slit2, and
Slit3 [7]. The Slit1 gene is located on human chromosome 10q24.1, the Slit2 gene is located on human chromosome 4p15.31, and the Slit3 gene is located on human chromosome 5q34-35.1 [8]. The Slit protein consists of five regions: one $\mathrm{N}$-terminal signal peptide, four leucine-rich domains (LRR, D1-D4) in tandem with disulfide bonds, six epidermal growth factor-like (EGF-like) domains, an Agrin-Perlecan-Laminin-Slit/Laminin-G-like domain, one (invertebrates) or three (vertebrates) epidermal growth factor (EGF) domains, and a C-terminal cysteine-rich knot $[9,10]$ (Figure 1A). Protein structural studies showed that Slit protein plays a regulatory role by binding to the first $\mathrm{Ig}$ of Robo1 at the second LRR domain [11] (Figure 2B), whereas two Slit2 proteins can unexpectedly bind to each other at the fourth LRR domain to form homodimers [12]. The Slit protein is cleaved by proteolytic enzymes between the fifth and sixth EGF-like domains to generate the long N-terminal Slit segment (SlitN) and the short C-terminal Slit segment (SlitC) (Figure 2A).

The SlitN fragment combines with Robos to mediate various life activities, while the SlitC 
fragment cannot bind to Robo [13]. SlitC has long been considered as a fragment without a regulatory function until recent studies reported that the SlitC fragment was found to be involved in the regulation of the protein kinase A (PKA) pathway in adipocyte thermoregulation and glucose metabolism [14] and mediated neuronal axon guidance by binding to the

A

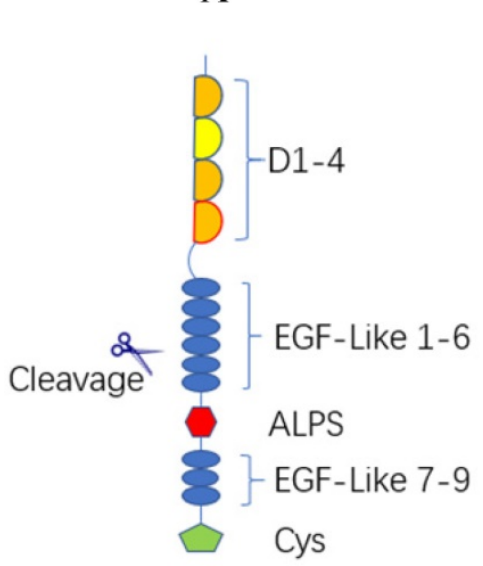

Slits plexin receptor [13, 15] (Figure 2A). More recently, a report argued that a Slit2 variant that lacks exon 15 in the D2 domain plays a different role in lung cancer [16] (Figure 3). Overall, the function of different Slit protein fragments after translation or different types must be determined further.

\section{$\mathrm{B}$}

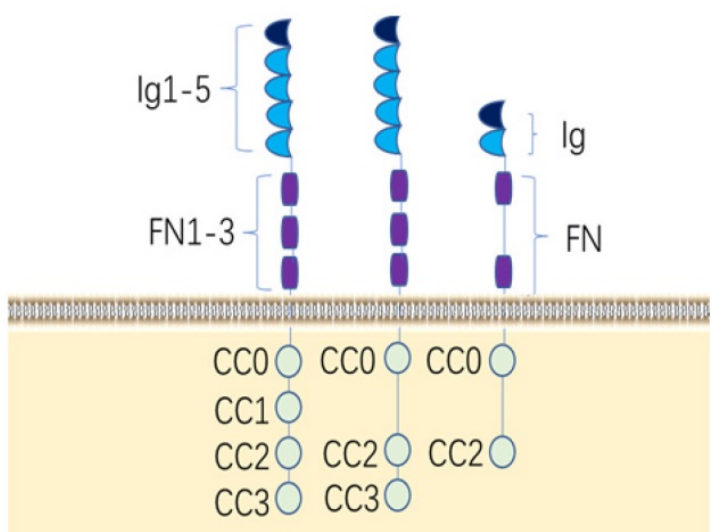

Robo1 Robo3 Robo4 Robo2

Figure 1. Structure of the Slit/Robo protein family and their interaction. (A). Structure of the human Slit protein. Slits consist of five regions as follows: one N-terminal signal peptide, four leucine-rich domains (LRR, D1-D4) in tandem with disulfide bonds, six epidermal growth factor-like (EGF-like) domains, an Agrin-Perlecan-Laminin-Slit (ALPS)/Laminin-G-like domain, three epidermal growth factor-likedomains, and a C-terminal cysteine-rich knot. Slits are proteolytically cleaved between EGF-like domains. (B). Structure of the human Robo protein. The extracellular domains of the Robol-3 proteins have the same structures, including 5 immunoglobulin domains, 3 fibronectin domains and one transmembrane domain. The Robo4 extracellular domain has only 2 immunoglobulin domains, 2 fiber connexin domains and one transmembrane region; the Robol and Robo2 intracellular region contains four conserved proline-rich domains, referred to as CC0-CC3. The Robo3 intracellular domain contains CCO, CC2 and CC3, and Robo4 only contains $\mathrm{CC} 0$ and $\mathrm{CC} 2$.

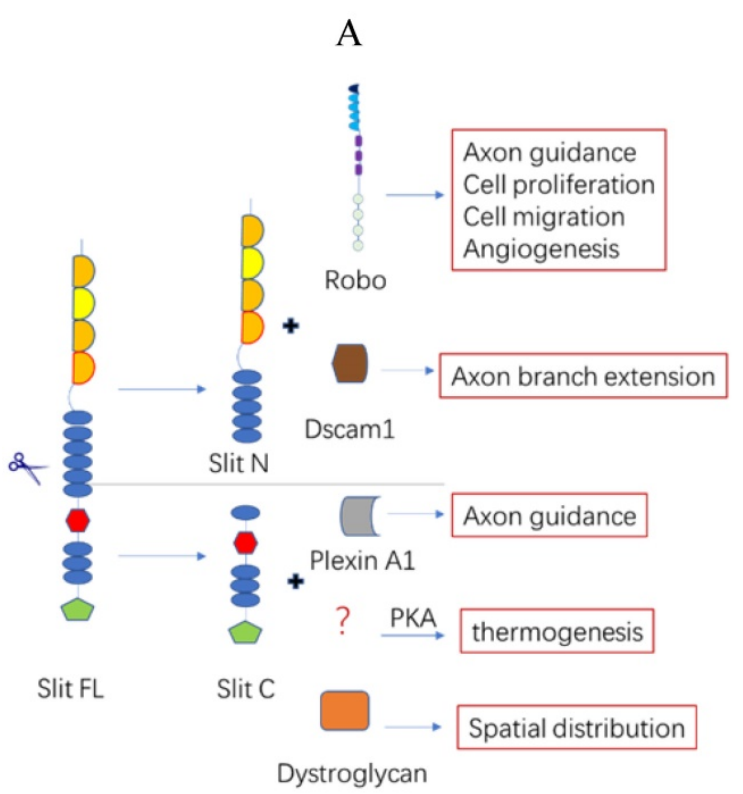

B

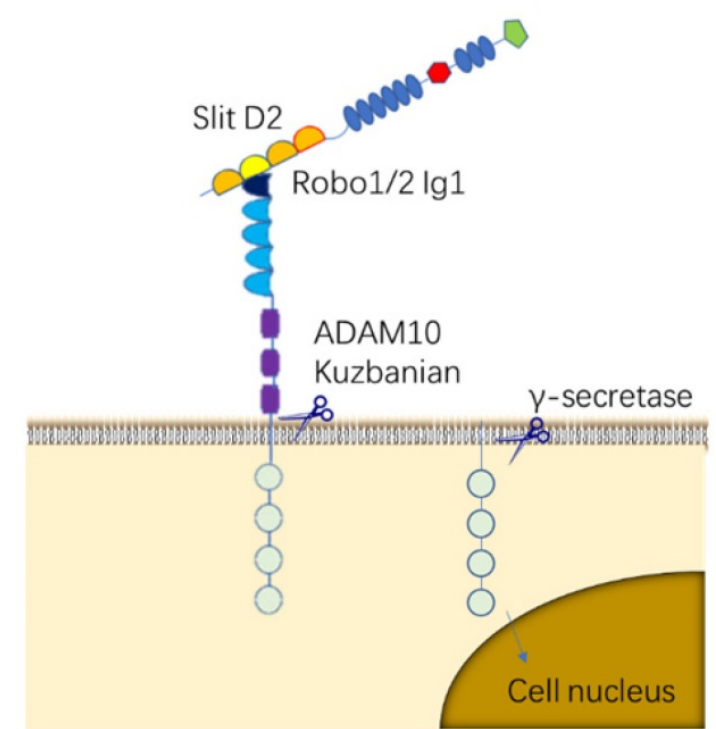

Figure 2. Slit/Robo protein proteolytic processing. (A). Slit protein proteolytic processing. Full-length Slit ligands are cleaved between the fifth and sixth EGF-like domains to create an $\mathrm{N}$-terminal fragment (Slit $\mathrm{N}$ ) and a C-terminal fragment (Slit $\mathrm{C}$ ), both of which combine with different receptors and serve strikingly different functions. (B). Robo protein proteolytic processing. Slit protein in the extracellular matrix binds to the first Ig of Robol at the second LRR structure and creates tension in the Robo juxtamembrane domain, allowing metalloprotease ADAM10 Kuzbanian to cleave the Robo ectodomain. The remaining segment may be hydrolyzed further by $\mathrm{Y}$-secretase and enter the nucleus to initiate downstream molecules. 


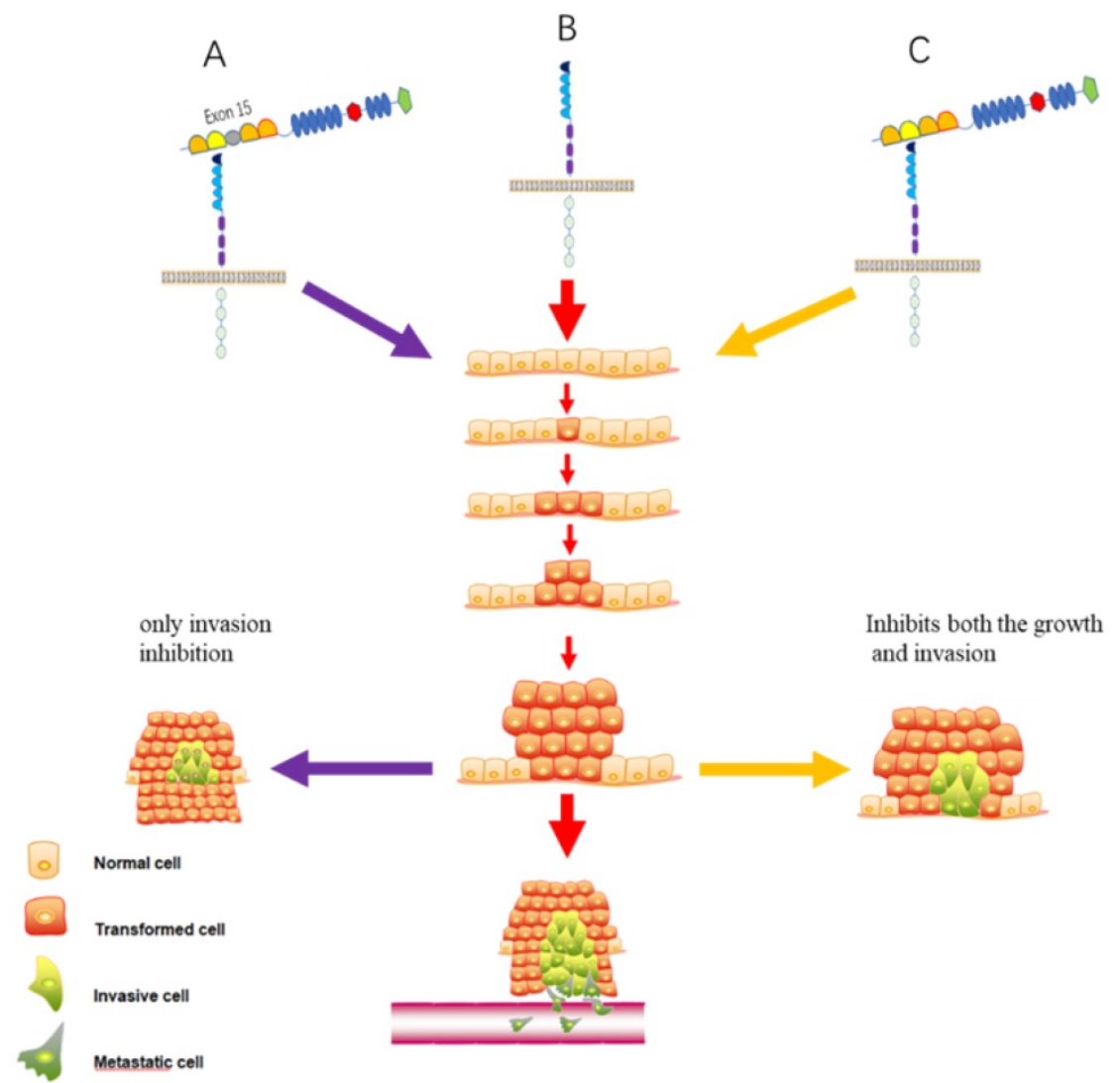

Figure 3. The function of two kinds of Slit2 in lung cancer. (A). Slit2-WT (presence of exon 15) possesses only invasion inhibitory activity. (B). Empty Slit2 is a control. (C). Slit2- $\Delta E 15$ (absence of exon 15) inhibits both the growth and invasion of CL1-5 lung cancer cells.

\section{Structural characteristics of Robo protein}

Robo proteins are a class of transmembrane receptor proteins with 1000 to 1600 amino acids and have highly conserved intracellular domains with no autocatalytic or intrinsic enzymatic activity. Nematodes have one Robo receptor (Sax-3, sensory axon guidance receptor 3) [17], Drosophila, chickens, and Xenopus have three Robo receptors called Robo1, Robo2 and Robo3 [18, 19], and zebrafish and mammals have four Robo receptors (Robo1-4) [20]. The Robo1 and Robo2 genes located in the human chromosome at 3p12.3, and Robo3 and Robo4 genes located in the human chromosome 11q24.2. The extracellular domains of the Robo1-3 proteins have the same structure, which includes 5 immunoglobulin domains, 3 fibronectin domains and one transmembrane domain. The extracellular Ig4 (D4) of Robo2 is the dimerization domain to facilitate the recruitment and activation of enzymatic effectors to instigate intracellular signaling [21]. The Robo4 extracellular domain consists of only 2 immunoglobulin domains and 2 fiber connexin domains and one transmembrane region. The Robo1 and Robo2 intracellular region contains four conserved proline-rich domains, referred to as $\mathrm{CC} 0-\mathrm{CC} 3$; the Robo3 intracellular domain contains
CC0, CC2 and CC3, whereas Robo4 only contains CC0 and CC2 [7, 20] (Figure 1B).

Robo proteins with no autocatalytic and intrinsic enzymatic activity in the intracellular region mediate downstream signaling through the recruitment of different adaptors or proteins. Notably, Robos can be selectively cleaved into different subtypes after transcription, and the consequence of its extracellular domain loss after translation and the interaction between different Robo receptors increase the diversity and complexity of their function [22-24] (Figure 2B).

\section{Divergent members of the Robo family}

Robo4 was long regarded as a specific receptor for vascular endothelia cells until very recently, when a study indicated that Robo4 can also exist in the newborn cerebral cortex to regulate the radial migration of newborn neurons [25]. Although Robo4 can be coimmunoprecipitated together with Slit2 in earlier studie [20], latter it was proved that it cannot bind to Slits directly but binds to the complex of Slit2 and Robo1 using biostructural techniques [11, 26]. Nevertheless, another studie showed that Robo4 as a ligand binds to UNC5B (a netrin receptor, also called Protein unc-5 homolog B) and inhibits VEGF-induced angiogenesis and vascular permeability, not as a 
receptor binds to Slit2 [27]. Meanwhile, some researchers proposed that Robo4 transduces signals through the development of a coreceptor with other molecules, such as Robo1, heparan sulfate proteoglycans (HSPGs) [11, 28]. Like the controversial results of Robo4, current evidences suggested that the role of Robo3 is also uncertain. For example, Zelina et al. contended that Robo3 cannot bind to Slits because of its specific difference in the Ig1 region in axon guidance but binds to Netrin-1/ Deleted in colorectal carcinoma (DCC) [29]. Another study observed that Robo3 antagonized the Slit2-Robo1/2-induced repulsion effect by binding to to neural EGFL Like 2 (NELL2), not by binding to Slit or Netrin-1, allowing the commissural axons to pass through the midline [30]. Therefore, Robo4 and Robo3 are two unique receptors which were endowed with much uncertainty, how and whether it binds to Slit ligand in regulating cell activities is yet to be determined.

\section{Slit/Robo signaling pathway}

Slits interact with Robos and subsequently play an important role in muscle cell formation, cell migration, stem cell growth, angiogenesis, organ development, and tumor formation by recruiting different adaptor molecules or proteins to cause a cascade of signaling pathways, but little is known about how exactly Slit binding to Robo is transmitted across the cell membrane. Many analysises showed that the ectodomain (ECD) is mainly responsible for Robo1-Robo1interactions [31, 32], and further studies indicate that this was largely mediated by the Ig domains of Robo1/2 in vitro [21]. Aleksandrova N recently indicated that the Robo1 ECD folds back on itself in a looping configuration, thereby forming a larger tetrameric structural arrangement consisting of a "dimer-of-dimers" in a putative inactive conformation [33]. The result was consistent with a mechanistic model in which a Slit2-N-induced conformational change of Robo1/2 is required for receptor activation [21, 31, 32].

However, increasing evidences suggested that Slit binds to other molecules, receptors or coreceptors in addition to Robo. Heparan sulfate proteoglycan (HSP) binds to both Slit and Robo to form a ternary complex to stabilize their interaction at the membrane [34]. Slits can also bind to extracellular matrix (ECM) molecules such as Plexin A [15], IV collagen [35], Netrin-1 [19], and dystroglycan [36]. Additionally, another study demonstrated that Slit combines with Dscam1, subsequently enhances the binding between Down syndrome cell adhesion molecule 1 (Dscam1) and Receptor Protein tyrosine phosphatase 69D (RPtp69D), and promotes Dscam1 dephosphorylation, which ultimately promotes axon formation
(Figure 2A) [37]. In terms of the function of combining with other ECM, Barak et al. investigated the Robo1 membrane-proximal domain and hypothesized that the combination of Slit and extracellular matrix molecules increases intermolecular tensions and allows Slit to bind tightly to the juxtamembrane region of Robo1 [38].

A similar phenomenon was also shown in numerous reports for Robo, which binds to other molecules apart from Slit, such as fibronectin leucine rich transmembrane protein 3 (FLRT3), NELL2, Unc5B [27, 30, 39]. The ability of Robo to bind to other molecules will be elucidated in following parts of our review and so will not be discussed further here. Overall, the variable combinations of Slit and Robo depending on different environments may explain the complexity of the Slit/Robo signaling pathway and may provide a rational explanation for the paradoxical observations in different studies.

\section{Downstream targets of Slit/Robo}

The signaling molecules downstream of Robos are mainly cytoplasmic kinases, and regulatory molecules associate with actin polymerization and microtubule cytoskeleton reorganization (Figure 4), which all contribute to impact the cell mobility, including kinases comprising Hakai, Myo9b, and GTPases containing the Rho-family (Rac, Cdc42 and RhoA), and some key regulators of cytoskeleton, like Abl, Ena.

Ab1 is actual involved in the Robo signaling pathway. It was recently demonstrated that $\mathrm{Abl}$ tyrosine kinase $(\mathrm{Abl})$ can inhibit Robo signaling by phosphorylation of the Robo CC1 domain after binding to Robo [40] and promotes Robo signaling by binding to Capulet protein or Cables protein to affect the activity of $\beta$-catenin and $\mathrm{N}$-cadherin, eventually alter cell adhesion [41, 42]. P-cadherin can also be impacted by Robo3 to regulate cell-cell adhesion [43]. GTPases are small GTP-binding proteins that regulate cell polarity and cell motility by modulating the cytoskeleton. The activity of GTPases is regulated by different functional proteins, such as Dock/Nck (Nck in mammals), s/rGAPs (Slit/RoboGTPase activating proteins) and GEFs (guanine nucleotide exchange factors), all which can be recruited by Robos in published papers [44-46]. The enabled (Ena) protein, a family of proline-rich proteins that positively regulate cellular actin formation and cell motility, which plays an important role in the axonal repulsion of filopodia assembly and extension mediated by Slit $[47,48]$.

There are de novo targets published recently that Slit/Robo can bind and recruit to promote cancer cell migration and weaken cancer cell adhesion, such as a ubiquitin kinase Hakai, which leads to the 
ubiquitination of E-cadherin, and Myo9b (or myosin IXB), which inhibits the growth and migration of lung cancer cells by inhibiting RhoA protein [49, 50]. Altogether, it is well-estimated that these melocules like Abl, Ena, GTPases and other targets of Slit/Robo regulate cell motility and migration. Hence, Slit/Robo may be a potential therapeutic target to impede disease development, like tumor.

\section{Regulatory molecules of Slit/Robo}

Many studies demonstrated that Slits/Robos are regulated at either the genetic or protein level in a variety of ways, such as by DNA, RNA and protein modification (Figure 5), which plays an important role in physiologic and pathologic processes.

The promoter region of the Slit and Robo genes are frequently downregulated via hypermethylation in tumors, including non-small cell lung cancer, breast cancer, glioma, hepatocellular carcinoma, colorectal cancer, and leukemia [51-57]. In addition, the expression of Slit2 can also be downregulated by the epigenetic modification enzyme EZH2 (enhancer of zeste 2 polycomb repressive complex 2 subunit) in prostate and brain cancer [58, 59].

The result first reported in our laboratory that Robo1 and Robo2 are negatively regulated by
miR-218 [60-62], was eventually verified by many other investigators [53, 56, 63, 64]. More recently, it was shown that Robo3 is negatively regulated by miR-383 and Robo1 is suppressed by miR92 [65, 66]. Robo2 protein may be a downstream target of the JAK/STAT pathway [67]. It has reported that Robo3 can antagonize Robo1/2 signaling [30], while Robo1/2 and Robo3 have synergistic effects in another study [68], so it can speculate that molecules unrecognized in between can regulate Robo. Moreover, Ubiquitin-specific protease 33 (USP33), a deubiquinating enzyme, stalblizes Robo1 by deubiquitinating it in lung cancer and colorectal cancer [55, 69]. Like the expression of Slit downregulated by hypermethylation, there are also reports showed that Robo can be hypermethylated in a few of cancer diseases [70,71]. In summary, these datas suggested that Slits and Robos can be regulated in many patterns to influence cell activities. Given that Slit/Robo plays an important role in tumor or dysplastic disease development, it is rational to speculate that upstream molecules may also be a cluster of promising targets to restrain these diseases' progression.

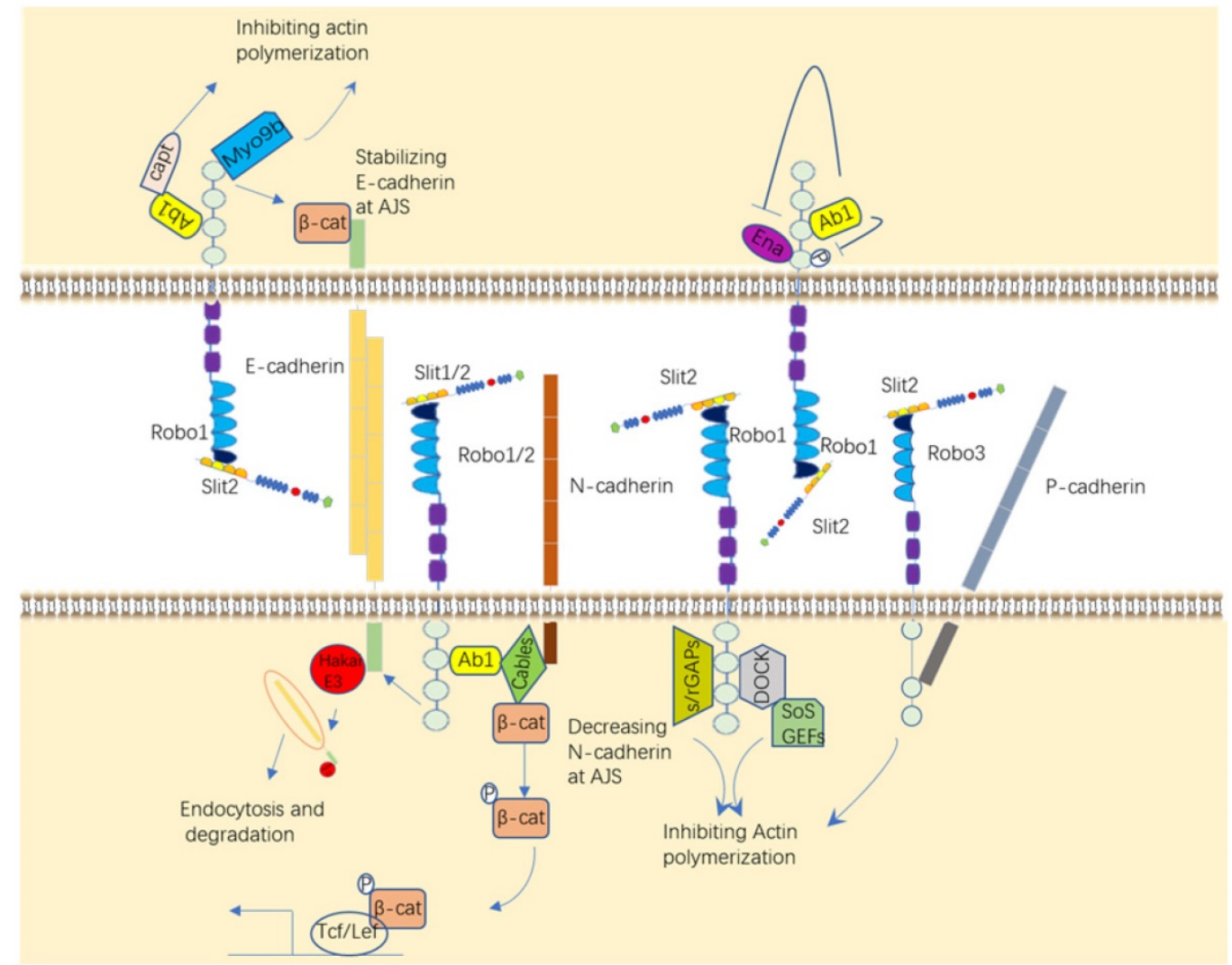

Figure 4. Downstream targets of Slit/Robo. Slit/Robo signaling participates in various activities through different kinases to influence cell motility. These molecules include AbI, GTPases, Ena, Hakai, and Myo9b. 


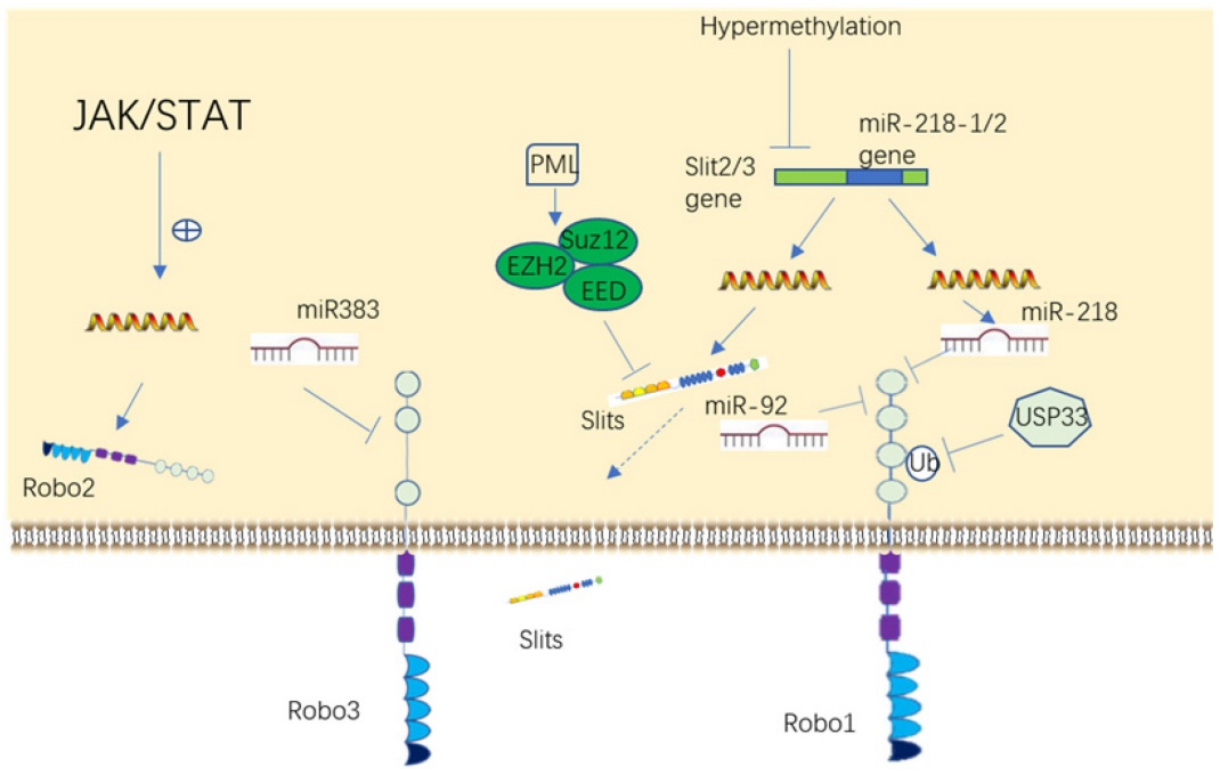

Figure 5. Upstream regulatory molecules of Slit/Robo. Slit and Robo can be regulated either at the genetic or protein level in a variety of ways, such as through DNA, RNA and protein modification.

\section{Roles of Slit/Robo in cell motility}

Slit/Robo was first reported in the nervous system and acted as an extracellular signpost to guide neuronal axon path finding, branching and control neuronal migration. Cells that are positive for Slit protein attract or repulse cells positive for Robo protein in one direction, which leads to cell migration. However, the function of Slit/Robo has been found to extend far beyond neurogenesis, including neurocyte development, angiogenesis, leukocytic chemotaxis, and cancer metastasis. The following section provides an overview of how this ligand-receptor functions in a variety of cells, which can be summed up as the roles of Slit/Robo in cell motility.

\section{The role of Slit/Robo in neurocyte navigation}

Nervous system development requires that the axons of neurocytes navigate to their correct location. Pathfinding is directed by molecular cues sensed by receptors in the axonal growth cone. Slits normally transmit signals through Robo family receptors. All three Slits are expressed by the floor plate, and commissural neurons express Robo1, Robo2, and Robo3. Slits bind Robo1 and Robo2 with high affinity to mediate neuro axon migration [7, 66, 72-74]. Interestingly, several developments suggested that untraditional receptors or coreceptors bind with ligands to regulate neuron axguidance (Figure 6).

Recently, one study established that Plexin A1, a well-known semaphoring receptor, is also a receptor for Slits during commissural axon guidance and reported for the first time that the C-terminal fragment generated by Slit processing has crucial bioactivity in axon branching [15]. Additionally, in the formation of thalamocortical connections, FLRT3 has been identified as a coreceptor for Robo1 and can modulate axonal responsiveness to Netrin [39]. Although Robo3 mentioned above does not bind to Slit proteins due to its specific difference in the Ig1 region [29], it was even reported that Robo3 can regulate midline crossing by antagonizing Robo1/2-mediated repulsion from midline-expressed Slits and potentiating DCC-mediated midline attraction to Netrin-1, without binding to Slits [29, 75]. Another unhomogeneous ligand was also reported to bind to Robo3 to control midline crossing, like NELL2 [30]. Robo4, which was initially considered to be solely expressed in endothelial cells, was not identified as a regulator in the neuronal system until a study argued that Robo4 is expressed in the developing brain and regulates the radial migration of newborn neurons in the neocortex [25]. Taken together, it is undoubted to conclude that Slit/Robo signaling de facto takes part in the growth of neuro axons through either its cognate or nonhomologus counterparts in different contexts. Notably, more determining researches should be conducted to make it as a possible potential target in neurological disorder.

\section{The role of Slit/Robo in angiogenesis}

Normally, Slit2 and Slit3 are secreted by vascular smooth muscle cells, endothelial cells and perivascular cells. Robo4, Robo1 and Robo2 are expressed in all kinds of endothelial cells [1]. Slit/Robo signaling regulates angiogenesis by altering endothelial cell motility and polarity. An increasing 
number of studies highlighted the role of Slit/Robo signaling during angiogenesis and the formation of blood vessels from existing vessels, but the conclusions drawn were not completely consistent with each other (Figure 7).

For a long time, the role of Slit/Robo signaling in angiogenesis was deemed to be to promote angiogenesis by binding to Robo1 or Robo1/Robo4 heterodimers [26, 76-79]. Investigations carried out in our laboratory also proved that Slit2/Robo1 triggers angiogenesis in gastric cancer [61]. Nevertheless, the opposite effect of inhibiting angiogenesis was later reported for Slit2/Robo4 signaling [80-83]. One research viewed that the angiogenic effect of Slit2 on endothelial cells is related to the ratio of Robo1 and Robo4 in endothelial cells [84]. These researchers found that Slit2 promoted the migration of human umbilical vein endothelial cells (HUVECs) by binding to Robo1 only after Robo4 was knocked down [84]. However, another explanation for why Slit2 plays two

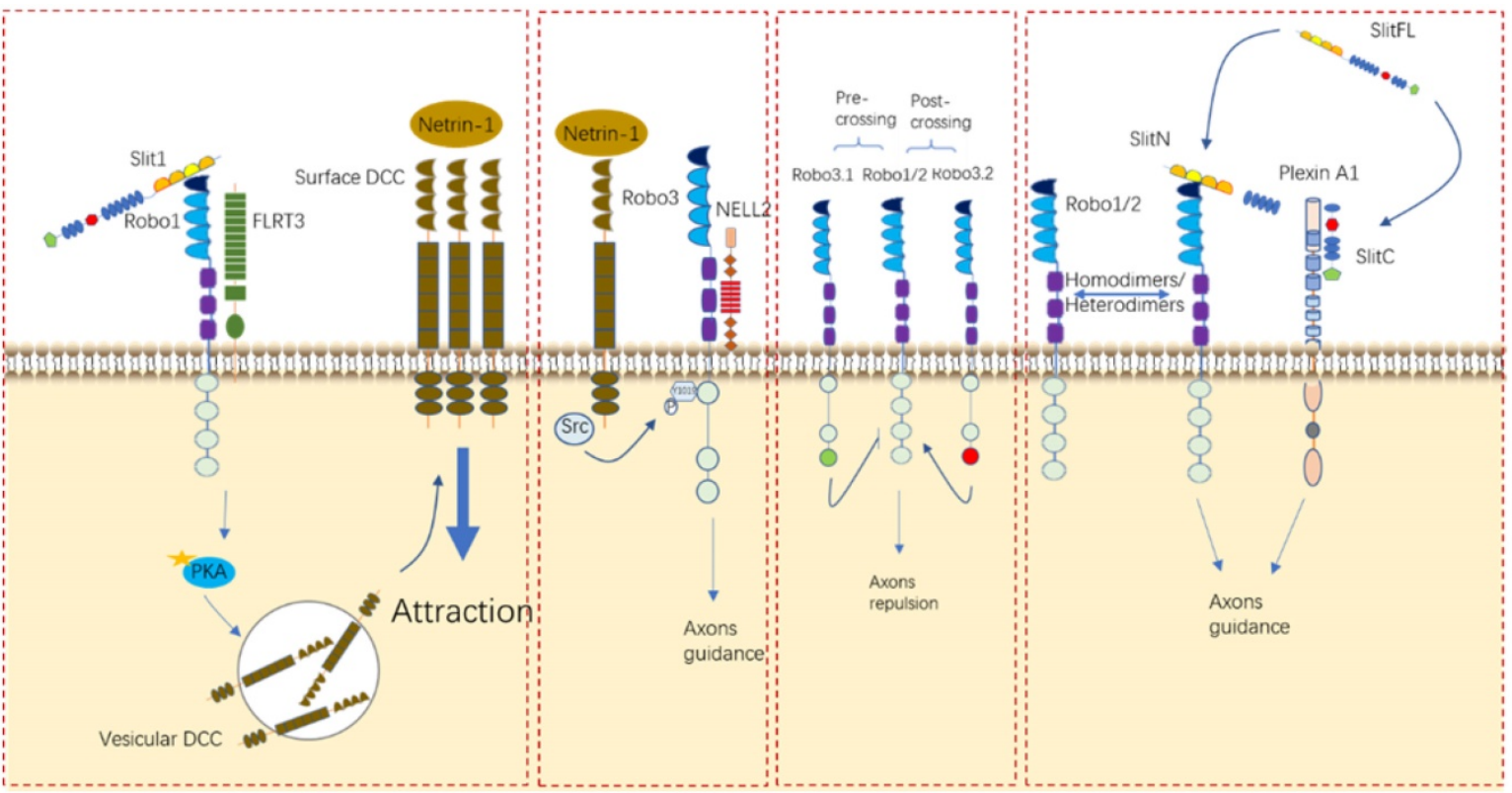

Figure 6. Roles of Slit/Robo in neurocyte navigation. Robo receptors can interact with other receptors, such as FLRT3, DCC, and NELL2, and form homodimers and/or heterodimers to elicit their functions in different contexts.

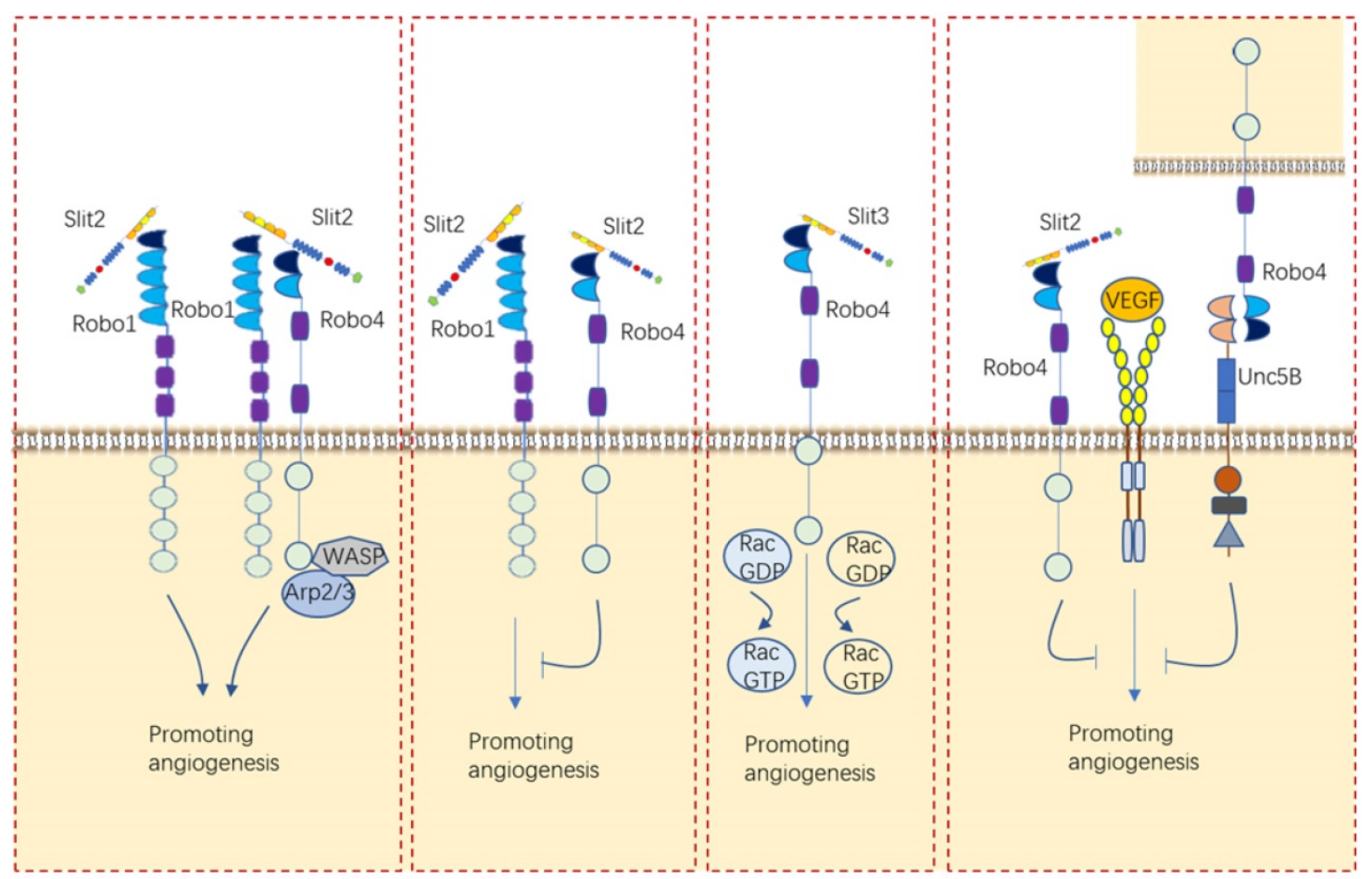

Figure 7. Roles of Slit/Robo in angiogenesis. Slits/Robos can alternatively bind with Robol or Robo4 or cooperate with VEGF to balance vascular vessel development. 
implausible contrary roles in angiogenesis, proposed by Dunaway, C.M. is that Slit2 alone promotes tumor angiogenesis but suppresses tumor angiogenesis when coexisting with ephrinA1 [85]. In addition to the role of Slit2 in angiogenesis, Slit3 had been shown to induce endothelial cell migration through Robo4, which activates Rac1 and RhoA [86]. These envidences indicated that Slit/Robo signaling can either promotes angiogenesis or inhibites angiogenesis via different receptors.

Other angiogenetic factor like VEGF/VEGFR can be impacted by Slit/Robo signaling in angiogenesis. For example, Slit2/Robo4 can inhibit VEGF-induced endothelial permeability and maintain vascular stability by recruiting GAPs to inhibit the activity of Arf6 and Rac [87]. Another study further viewed that Robo4 binds UNC5B and inhibits VEGF/VEGFR signaling, thus stabilizing blood vessels and inhibiting angiogenesis [27].

Interestingly, Slits expressed by different cell sources have distinct functions in angiogenesis. Marlow $\mathrm{R}$ et al found that vascularization of the breast gland is not affected by loss of Slit expression in the epithelial compartment [81]. Instead, they identified a stromal source of SLIT, mural cells encircling blood vessels, and showed that loss of Slit in the stroma leads to elevated blood vessel density and complexity [81]. Eventually, they clarified that Slit2/Slit3 expressed by mural cells encircling blood vessels in the stroma, rather than those expressed by the epithelium, inhibits VEGF-induced angiogenesis via Robo4 but not Robo1 [81].

Together with these findings, it is difficult to determine exactly the regulating role of Slit/Robo in angiogenesis. In view of studies had shown that Slit/Robo signaling inhibits VEGF-induced vascular formation and so another method can be utilized for VEGF targeting drug resistance in many carcinomas' treatment, such as bevacizumab and sorafenib.

\section{The role of Slit/Robo in leukocyte chemotaxis}

Slit was initially identified as an inhibitor of leukocyte chemotaxis by $\mathrm{Wu}$ et al [88]. They used transwell migration assays to domenstrate that lymphocytes and leukocytes in response to various chemoattractants is inhibited by Slit2 [88]. Tole $S$ et al. further domenstrated that Slit2 selectively impaired neutrophil migration toward other chemoattractants, namely, C5a and IL-8, and inhibited neutrophil chemotaxis by preventing chemoattractant induced actin barbed end formation and cell polarization [89]. In the model of renal ischemia-reperfusion injury, Slit2 blocked the capture and firm adhesion of human neutrophils to the inflamed vascular endothelial barrier by suppressing the inducible activation of
Cdc42 and Rac2, which are critical mediators for cell migration [90]. Another observation in a mouse model that Slit2 significantly reduces the recruitment of neutrophils to the site of inflammation is in accordance with other inflammation models, including glomerulonephritis-associated kidney injury, global cerebral ischemia, and skin sensitization to allergens [91-93]. Interestingly, one study from a different perspective found that Slit/Robo4 strengthens the vascular barrier and diminishes deleterious aspects of the host's response to the pathogen-induced cytokine reaction [94]. Collectively, these evidences showed Slit/Robo inhibits chemotaxis of leukocytes toward chemoattractants, and it may have a therapeutic role as an inhibitor of inflammatory cell infiltration.

On the contrary, a recent paper suggested that Slit2 can also cause chemorepulsion of human neutrophils other than chemoattraction [95]. In their report, the authors showed that Slit2 comprises $\sim 140-k D a$ N-terminal Slit2 fragment (Slit2-N), which serves as a chemoattractant for human neutrophils, and $\sim 110-\mathrm{kDa}$ N-terminal Slit2 fragment (Slit2-S), which serves as a chemorepellent for human neutrophis [95]. They further found that the effects of both Slit2 fragments were blocked by Abs to the Slit2 receptor Roundabout homolog 1 or the Slit2 coreceptor Syndecan-4, but involved in different intracellular signaling pathways [95]. These evidences remind of us that numerous works are needed to determining the clear role of Slit/Robo in leukocyte regulation.

\section{The role of Slit/Robo in cancer metastasis}

Like the role of Slit/Robo signaling in axon guidance, in which the proteins have dual attraction and repulsion effects, the role of Slit/Robo in cancer cell migration varies in certain contexts. A variety of studies showed that the expression of Slit is downregulated or not detected in most tumors, including breast cancer [96], gastric cancer [53], lung cancer [97], liver cancer [98], esophageal cancer [54] and others [99], and is largely related to promoter hypermethylation, indicating the inhibitory effect of Slit/Robo in these cancers, which is consistent with our studies in gastric cancer [60-62]. In contrast, overexpression of Slit and Robo appear in some tumors, such as melanoma [76], gastric cancer [100], pancreatic cancer tissues and cell lines [65], and hepatocellular carcinoma [101], which demonstrates that Slit/Robo signaling has a facilitating effect in certain cancers. The process of migration and metastasis of tumor cells was driven by stimulatory molecules such as Slit/Robo within the environment, which involves the process of reducing adhesion 
between cells, reassembling the cytoskeleton, inducing chemotaxis, enhancing angiogenesis, interrupting lymphogenesis and innervation.

Emerging evidences suggested that Slit/Robo signaling alters tumor cell-cell adhesion by regulating the connection between E-cadherin, a signaling target that is important for the maintenance and stability of cells, tissues and organs, and $\beta$-catenin, a signaling target that translocates into the nucleus to activate Lef/Tcf after activating [42, 49, 65, 97, 102, 103]. Of note, P-cadherin was also involved in regulating cell-cell adhesion by combining with Robo3 in oral squamous cell carcinoma [43].

In addition to reducing cell-cell adhesion, the assembly of cytoskeletal actin and the dissolution of the extracellular matrix can be impacted by Slit/Robo signaling to regulate cancer cell metastasis. Parray et al. used wound healing migration assay to demonstrate that prostate cancer cell migration was inhibited by Slit 2 through inactivating Rac protein in the experimental model of Robo1 mutations in the C2 and C3 loci [70]. Another study suggested that Slit2 inhibits esophageal cancer cell metastasis by inhibiting Cdc42, FAK and Paxillin protein activities [54]. We and Kong et al. showed that in lung cancer, Slit2/Robo1 inhibited lung cancer cell migration via inhibiting the Myob/RhoA signaling pathway [50]. Meanwhile, Yuan, $\mathrm{M}$ et al. showed high expression of slit2 and down-regulation of Robo1 markedly enhanced migration of hepatic cancer cell [104]. The authors demonstrated that Robo1 overexpression upregulated matrix metalloproteinase (MMP)-2, MMP-9, and membrane-type1 MMP (MT1-MMP) expression, thereby promoting tumor metastasis [104]. In malignant melanoma, MMP2 and MMP14 was showed to be downregulated by Slit3/Robo2 and thereby inhibiting cancer cell migration [105]. They demonstrated that by binding to Robo3, the Slit3 suppressed the expression of AP1 and then downregulated its targeted genes expression [105].

To survive under hypoxic hazardous, conditions, cancer cells shift their metabolism pattern, known as Warburg effect (or hypoxic adaption) to meet demands of sustainable growth and metastasis. By knocking down Slit2 expression, Shi, R. L et al. demonstrated that Warburg effect was utilized by Slit2 to inhibit the metastasis of thyroid cancer cells [106]. More recently, Jeon MJ et al. observed a similar role of Slit in thyroid cancer cell migration that Slit3 also involved in inhibiting thyroid cancer cell migration but by regulating beta-catenin and Rho GTPase activity [107].

Additional mechanisms were also reported in papers. CXCL12/CXCR4- induced breast cancer cell chemotaxis, chemoinvasion and the adhesion, the foundmental components that promote metastasis was inhibited by slit2 [108, 109]. The authors revealed that Slit2 inhibits CXCL12-induced tyrosine phosphorylation of focal adhesion components such as RAFTK/Pyk2 at residues 580 and 881, focal adhesion kinase at residue 576, and paxillin [108]. Another study demonstrated that in breast cancer patients, glioblastoma cells with high Slit2 promoted the migration of siRobo1/breast cancer cells compared with the Slit2 absent group [110]. Thereby, the authors hypothesized that high level of Slit2 in brain serving as a chemoattractant to attract breast cancer cells with lower level of Robo1 [110]. Taken together, these evidences suggest that Slit can impact other chemokines or serve as chemokine to regulate cancer cell migration other than traditional pathway.

By using immune competent Robo4 knockout mouse model, Robo4 was showed that it played a very important role for suppressing breast cancer growth and metastasis by regulating tumor angiogenesis, endothelial leakage and tight junction protein zonula occludents protein (ZO-1) downregulation [82]. Due to the lymphatic system plays critical roles in the maintenance of fluid homeostasis, immune response, and tumor metastasis, $\mathrm{Yu}, \mathrm{J}$. et al. demonstrated that Slit2N/Robo4 modulates lymphatic dysfunction characterized by VEGF-C/VEGFR3 activation and this ligand-receptor pair may be a potential drug target to inhibit cancer metastasis [111]. Meanwhile, another study suggested that Slit2 Inhibits Neural Invasion and Metastasis in Pancreatic Cancer [112]. The authors demonstrated that SLIT2 mRNA expression was reduced in Pancreatic ductal adenocarcinoma (PDAC) compared with nontransformed pancreatic tissues and cell lines, suggesting a reduction in Slit2/Robo pathway activity in PDAC [112]. In according with the interpretation, restoring the SLIT2 expression in SLIT2- deficient PDAC cells inhibited their bidirectional chemoattraction with neural cells, and impaired unidirectional PDAC cell navigation along outgrowing neurites in models of neural invasion [112]. Collectively, these studies revealed that Slit/Robo can also impact cancer metastasis indirectly by interrupting angiogenesis, lymphogenesis and innervation.

\section{Conclusions and perspectives}

From the findings mentioned above, despite the high diversity of functional processes mediated by Slit/Robo signaling in different cells, it is reasonable to speculate that the regulation in various activities by Slit/Robo are correlated with altering cell motility. The reason that complex phenotypes related to 
Slit/Robo signaling can be attributed to the innumerous ligands or receptors involved in this pathway in different environments, and diverse outcomes could be caused by various molecules participating in this signaling pathway.

Encouragingly, several reports revealed beneficial outcomes by using Robo mAb therapy to treat cancer and vascular diseases. For instance, Fujiwara et al. uncovered a significant therapeutic effect by intravenous injection of Robo1 $\mathrm{mAb}$ in mouse hepatoma and non-small cell lung cancer tumor models [113, 114]. Mounting studies have demonstrated the potential anti-angiogenic role of Slit2 in corneal and retinal neovascularization, endometriosis and renal ischemia-reperfusion injury $[77,79,90,115]$. Therefore, the Slit/Robo signaling pathway might be a promising target in therapy for tumor or intractable diseases, like VEGF/VEGFR or EGF/EGFR. Further investigations should focus on context- and cell-dependent downstream signaling pathways that underlie cellular responses in different environments. Additionally, more research is needed to interpret the potential therapeutic effect of the Slit/Robo signaling pathway in animal and human genetic models because gene modification is the most vital experiment in studying genetic function.

\section{Acknowledgements}

The work was funded by the natural science foundation of china (No. 81430072, To Daiming Fan), the scientific fund for innovative research groups of the national natural science foundation of China (No. 81421003, To Daiming Fan) and fundamental research funds for national center for clinical medicine of digestive diseases (No. 2015BAI13B07, To Daiming Fan).

\section{Competing Interests}

The authors have declared that no competing interest exists.

\section{References}

1. Ballard MS, Hinck L. A roundabout way to cancer. Adv Cancer Res. 2012; 114: 187-235

2. Rothberg JM, Hartley DA, Walther Z, Artavanis-Tsakonas S. Slit: an EGF-homologous locus of D. melanogaster involved in the development of the embryonic central nervous system. Cell. 1988; 55: 1047-59.

3. Medioni C, Bertrand N, Mesbah K, Hudry B, Dupays L, Wolstein O, et al. Expression of Slit and Robo genes in the developing mouse heart. Dev Dyn. 2010; 239: 3303-11.

4. Macias H, Moran A, Samara Y, Moreno M, Compton JE, Harburg G, et al. SLIT/ROBO1 signaling suppresses mammary branching morphogenesis by limiting basal cell number. Dev Cell. 2011; 20: 827-40.

5. Zhang B, Xiao W, Qiu H, Zhang F, Moniz HA, Jaworski A, et al. Heparan sulfate deficiency disrupts developmental angiogenesis and causes congenital diaphragmatic hernia. J Clin Invest. 2014; 124: 209-21.

6. Fan X, Li Q, Pisarek-Horowitz A, Rasouly HM, Wang X, Bonegio RG, et al. Inhibitory effects of Robo2 on nephrin: a crosstalk between positive and negative signals regulating podocyte structure. Cell Rep. 2012; 2: 52-61.

7. Dickson BJ, Gilestro GF. Regulation of commissural axon pathfinding by slit and its Robo receptors. Annu Rev Cell Dev Biol. 2006; 22: 651-75.
8. Katoh $\mathrm{Y}$, Katoh $\mathrm{M}$. Comparative genomics on SLIT1, SLIT2, and SLIT3 orthologs. Oncol Rep. 2005; 14: 1351-5.

9. Rothberg JM, Artavanis-Tsakonas S. Modularity of the slit protein. Characterization of a conserved carboxy-terminal sequence in secreted proteins and a motif implicated in extracellular protein interactions. J Mol Biol. 1992; 227: 367-70.

10. Rothberg JM, Jacobs JR, Goodman CS, Artavanis-Tsakonas S. Slit: an extracellular protein necessary for development of midline glia and commissural axon pathways contains both EGF and LRR domains. Genes Dev. 1990; 4: 2169-87.

11. Morlot C, Thielens NM, Ravelli RB, Hemrika W, Romijn RA, Gros P, et al Structural insights into the Slit-Robo complex. Proc Natl Acad Sci U S A. 2007; 104: $14923-8$.

12. Seiradake E, von Philipsborn AC, Henry M, Fritz M, Lortat-Jacob H, Jamin M, et al. Structure and functional relevance of the Slit2 homodimerization domain. EMBO Rep. 2009; 10: 736-41.

13. Nguyen BCKT, Brose K, Ma L, Wang KH, Marillat V, Sotelo C, et al. Diversity and specificity of actions of Slit2 proteolytic fragments in axon guidance. J Neurosci. 2001; 21: 4281-9.

14. Svensson KJ, Long JZ, Jedrychowski MP, Cohen P, Lo JC, Serag S, et al. A secreted Slit2 fragment regulates adipose tissue thermogenesis and metabolic function. Cell Metab. 2016; 23: 454-66.

15. Delloye-Bourgeois C, Jacquier A, Charoy C, Reynaud F, Nawabi H, Thoinet K, et al. PlexinA1 is a new Slit receptor and mediates axon guidance function of Slit C-terminal fragments. Nat Neurosci. 2015; 18: 36-45.

16. Lin YY, Yang CH, Sheu GT, Huang CY, Wu YC, Chuang SM, et al. A novel exon 15-deleted, splicing variant of Slit2 shows potential for growth inhibition in addition to invasion inhibition in lung cancer. Cancer. 2011; 117: 3404-15

17. Zallen JA, Yi BA, Bargmann CI. The conserved immunoglobulin superfamily member SAX-3/Robo directs multiple aspects of axon guidance in C. elegans. Cell. 1998; 92: 217-27.

18. Connor RM, Key B. Expression and role of Roundabout-1 in embryonic Xenopus forebrain. Dev Dyn. 2002; 225: 22-34.

19. Brose K, Bland KS, Wang KH, Arnott D, Henzel W, Goodman CS, et al. Slit proteins bind Robo receptors and have an evolutionarily conserved role in repulsive axon guidance. Cell. 1999; 96: 795-806.

20. Park KW, Morrison CM, Sorensen LK, Jones CA, Rao Y, Chien CB, et al. Robo4 is a vascular-specific receptor that inhibits endothelial migration. Dev Biol. 2003; 261: 251-67.

21. Yom-Tov G, Barak R, Matalon O, Barda-Saad M, Guez-Haddad J, Opatowsky Y. Robo Ig4 Is a Dimerization Domain. Journal of Molecular Biology. 2017; 429: 3606-3616.

22. Blockus H, Chedotal A. Slit-Robo signaling. Development. 2016; 143: 3037-44.

23. Coleman HA, Labrador JP, Chance RK, Bashaw GJ. The Adam family metalloprotease Kuzbanian regulates the cleavage of the roundabout receptor to control axon repulsion at the midline. Development. 2010; 137: 2417-26.

24. Seki M, Watanabe A, Enomoto S, Kawamura T, Ito H, Kodama T, et al. Human ROBO1 is cleaved by metalloproteinases and gamma-secretase and migrates to the nucleus in cancer cells. FEBS Lett. 2010. 584: 2909-15.

25. Zheng W, Geng AQ, Li PF, Wang Y, Yuan XB. Robo4 regulates the radial migration of newborn neurons in developing neocortex. Cereb Cortex. 2012; 22. 2587-601.

26. Sheldon H, Andre M, Legg JA, Heal P, Herbert JM, Sainson R, et al. Active involvement of Robo1 and Robo4 in filopodia formation and endothelial cell motility mediated via WASP and other actin nucleation-promoting factors. FASEB J. 2009; 23: 513-22.

27. Koch AW, Mathivet T, Larrivee B, Tong RK, Kowalski J, Pibouin-Fragner L, et al. Robo4 maintains vessel integrity and inhibits angiogenesis by interacting with UNC5B. Dev Cell. 2011; 20:33-46.

28. Fukuhara N, Howitt JA, Hussain SA, Hohenester E. Structural and functional analysis of slit and heparin binding to immunoglobulin-like domains 1 and 2 of Drosophila Robo. J Biol Chem, 2008; 283: 16226-34.

29. Zelina P, Blockus H, Zagar Y, Peres A, Friocourt F, Wu Z, et al. Signaling switch of the axon guidance receptor Robo3 during vertebrate evolution. Neuron. 2014; 84: 1258-72.

30. Jaworski A, Tom I, Tong RK, Gildea HK, Koch AW, Gonzalez LC, et al. Operational redundancy in axon guidance through the multifunctional receptor Robo3 and its ligand NELL2. Science. 2015; 350: 961-5.

31. Liu Z, Patel K, Schmidt H, Andrews W, Pini A, Sundaresan V. Extracellular Ig domains 1 and 2 of Robo are important for ligand (Slit) binding. Mol Cell Neurosci. 2004; 26: 232-40.

32. Hivert B, Liu Z, Chuang CY, Doherty P, Sundaresan V. Robo1 and Robo2 are homophilic binding molecules that promote axonal growth. Mol Cell Neurosci. 2002; 21: 534-45.

33. Aleksandrova N, Gutsche I, Kandiah E, Avilov SV, Petoukhov MV, Seiradake E, et al. Robo1 Forms a Compact Dimer-of-Dimers Assembly. Structure. 2018; 26: 320-328.e4.

34. Steigemann P, Molitor A, Fellert S, Jackle H, Vorbruggen G. Heparan sulfate proteoglycan syndecan promotes axonal and myotube guidance by slit/robo signaling. Curr Biol. 2004; 14: 225-30.

35. Xiao T, Staub W, Robles E, Gosse NJ, Cole GJ, Baier H. Assembly of lamina-specific neuronal connections by slit bound to type IV collagen. Cell. 2011; 146: 164-76. 
36. Wright KM, Lyon KA, Leung H, Leahy DJ, Ma L, Ginty DD. Dystroglycan organizes axon guidance cue localization and axonal pathfinding. Neuron. 2012; 76: 931-44.

37. Dascenco D, Erfurth ML, Izadifar A, Song M, Sachse S, Bortnick R, et al. Slit and receptor tyrosine phosphatase 69D confer spatial specificity to axon branching via Dscam1. Cell. 2015; 162: 1140-54

38. Barak R, Lahmi R, Gevorkyan-Airapetov L, Levy E, Tzur A, Opatowsky Y. Crystal structure of the extracellular juxtamembrane region of Robo1. J Struct Biol. 2014; 186: 283-91.

39. Leyva-Diaz E, del Toro D, Menal MJ, Cambray S, Susin R, Tessier-Lavigne M, et al. FLRT3 is a Robo1-interacting protein that determines Netrin-1 attraction in developing axons. Curr Biol. 2014; 24: 494-508.

40. Bashaw GJ, Kidd T, Murray D, Pawson T, Goodman CS. Repulsive axon guidance: abelson and enabled play opposing roles downstream of the roundabout receptor. Cell. 2000; 101: 703-15.

41. Wills Z, Emerson M, Rusch J, Bikoff J, Baum B, Perrimon N, et al. A Drosophila homolog of cyclase-associated proteins collaborates with the Abl tyrosine kinase to control midline axon pathfinding. Neuron. 2002; 36: 611-22.

42. Rhee J, Buchan T, Zukerberg L, Lilien J, Balsamo J. Cables links Robo-bound $\mathrm{Abl}$ kinase to $\mathrm{N}$-cadherin-bound beta-catenin to mediate Slit-induced modulation of adhesion and transcription. Nat Cell Biol. 2007; 9: 883-92.

43. Bauer K, Dowejko A, Bosserhoff AK, Reichert TE, Bauer R. Slit-2 facilitates interaction of P-cadherin with Robo-3 and inhibits cell migration in an oral squamous cell carcinoma cell line. Carcinogenesis. 2011; 32: 935-43.

44. Feng Y, Feng L, Yu D, Zou J, Huang Z. srGAP1 mediates the migration inhibition effect of Slit2-Robo1 in colorectal cancer. J Exp Clin Cancer Res. 2016; 35: 191.

45. Dubrac A, Genet G, Ola R, Zhang F, Pibouin-Fragner L, Han J, et al. Targeting NCK-Mediated Endothelial Cell Front-Rear Polarity Inhibits Neovascularization. Circulation. 2016; 133: 409-421.

46. Fritz RD, Menshykau D, Martin K, Reimann A, Pontelli V, Pertz O. SrGAP2-Dependent Integration of Membrane Geometry and Slit-Robo-Repulsive Cues Regulates Fibroblast Contact Inhibition of Locomotion. Developmental Cell. 2015; 35: 78-92.

47. Barzik M, Kotova TI, Higgs HN, Hazelwood L, Hanein D, Gertler FB, et al. Ena/VASP proteins enhance actin polymerization in the presence of barbed end capping proteins. J Biol Chem. 2005; 280: 28653-62.

48. McConnell RE, van Veen JE, Vidaki M, Kwiatkowski AV, Meyer AS, Gertler FB. A requirement for filopodia extension toward Slit during Robo-mediated axon repulsion. J Cell Biol. 2016; 213: 261-74

49. Zhou WJ, Geng ZH, Chi S, Zhang W, Niu XF, Lan SJ, et al. Slit-Robo signaling induces malignant transformation through Hakai-mediated E-cadherin degradation during colorectal epithelial cell carcinogenesis. Cell Res. 2011; 21: 609-26.

50. Kong R, Yi F, Wen P, Liu J, Chen X, Ren J, et al. Myo9b is a key player in SLIT/ROBO-mediated lung tumor suppression. J Clin Invest. 2015; 125: 4407-20.

51. Shuai W, Wu J, Chen S, Liu R, Ye Z, Kuang C et al. SUV39H2 promotes colorectal cancer proliferation and metastasis via tri-methylation of the SLIT1 promoter. Cancer Letters. 2018; 422: 56-69.

52. Nones K, Waddell N, Song S, Patch AM, Miller D, Johns A et al. Genome-wide DNA methylation patterns in pancreatic ductal adenocarcinoma reveal epigenetic deregulation of SLIT-ROBO, ITGA2 and MET signaling. Int J Cancer. 2014; 135: 1110-8.

53. Kim M, Kim JH, Baek SJ, Kim SY, Kim YS. Specific expression and methylation of SLIT1, SLIT2, SLIT3, and miR-218 in gastric cancer subtypes. Int J Oncol. 2016; 48: 2497-507.

54. Tseng RC, Chang JM, Chen JH, Huang WR, Tang YA, Kuo IY, et al Deregulation of SLIT2-mediated Cdc42 activity is associated with esophageal cancer metastasis and poor prognosis. J Thorac Oncol. 2015; 10: 189-98.

55. Huang Z, Wen P, Kong R, Cheng H, Zhang B, Quan C, et al. USP33 mediates Slit-Robo signaling in inhibiting colorectal cancer cell migration. Int J Cancer. 2015; 136: 1792-802.

56. Alajez NM, Lenarduzzi M, Ito E, Hui AB, Shi W, Bruce J, et al. MiR-218 suppresses nasopharyngeal cancer progression through downregulation of survivin and the SLIT2-ROBO1 pathway. Cancer Res. 2011; 71: 2381-91.

57. Qiu H, Zhu J, Yu J, Pu H, Dong R. SLIT2 is epigenetically silenced in ovarian cancers and suppresses growth when activated. Asian Pac J Cancer Prev. 2011; 12: 791-5.

58. Yu J, Cao Q, Yu J, Wu L, Dallol A, Li J, et al. The neuronal repellent SLIT2 is a target for repression by EZH2 in prostate cancer. Oncogene. 2010; 29: 5370-80.

59. Amodeo VAD, Betts J, Bartesaghi S, Zhang Y, Richard-Londt A, et al A $\mathrm{PML} / \mathrm{Slit}$ axis controls physiological cell migration and cancer invasion in the CNS. Cell Rep. 2017; 20: 411-26.

60. Wang SM, Tie J, Wang WL, Hu SJ, Yin JP, Yi XF, et al. POU2F2-oriented network promotes human gastric cancer metastasis. Gut. 2016; 65: 1427-38.

61. Zhang X, Dong J, He Y, Zhao M, Liu Z, Wang N, et al. miR-218 inhibited tumor angiogenesis by targeting ROBO1 in gastric cancer. Gene. 2017; 615: 42-9.

62. Tie J, Pan Y, Zhao L, Wu K, Liu J, Sun S, et al. MiR-218 inhibits invasion and metastasis of gastric cancer by targeting the Robo1 receptor. PLoS Genet. 2010; 6: e1000879

63. Small EM, Sutherland LB, Rajagopalan KN, Wang S, Olson EN MicroRNA-218 regulates vascular patterning by modulation of Slit-Robo signaling. Circ Res. 2010; 107: 1336-44.
64. Yang M, Liu R, Li X, Liao J, Pu Y, Pan E, et al. Epigenetic repression of miR-218 promotes esophageal carcinogenesis by targeting ROBO1. Int J Mol Sci. 2015; 16: 27781-95.

65. Han S, Cao C, Tang T, Lu C, Xu J, Wang S, et al. ROBO3 promotes growth and metastasis of pancreatic carcinoma. Cancer Lett. 2015; 366: 61-70.

66. Yang T, Huang H, Shao Q, Yee S, Majumder T, Liu G. miR-92 Suppresses Robo1 Translation to Modulate Slit Sensitivity in Commissural Axon Guidance. Cell Reports. 2018; 24: 2694-2708.e6.

67. Stine RR, Greenspan LJ, Ramachandran KV, Matunis EL. Coordinate regulation of stem cell competition by Slit-Robo and JAK-STAT signaling in the Drosophila testis. PLoS Genet. 2014; 10: e1004713.

68. Couch JA, Chen J, Rieff HI, Uri EM, Condron BG. Robo2 and Robo3 interact with eagle to regulate serotonergic neuron differentiation. Development. 2004; 131: 997-1006.

69. Wen P, Kong R, Liu J, Zhu L, Chen X, Li X, et al. USP33, a new player in lung cancer, mediates Slit-Robo signaling. Protein Cell. 2014; 5: 704-13.

70. Parray A, Siddique HR, Kuriger JK, Mishra SK, Rhim JS, Nelson HH, et al. ROBO1, a tumor suppressor and critical molecular barrier for localized tumor cells to acquire invasive phenotype: study in African-American and Caucasian prostate cancer models. Int J Cancer. 2014; 135: 2493-506.

71. Narayan G, Goparaju C, Arias-Pulido H, Kaufmann AM, Schneider A, Dürst $\mathrm{M}$ et al. Promoter hypermethylation-mediated inactivation of multiple Slit-Robo pathway genes in cervical cancer progression. Molecular cancer. 2006; 5: 16-16.

72. Kim M, Fontelonga TM, Lee CH, Barnum SJ, Mastick GS. Motor axons are guided to exit points in the spinal cord by Slit and Netrin signals. Developmental Biology. 2017; 432: 178-191.

73. Kaneko N, Herranz-Pérez V, Otsuka T, Sano H, Ohno N, Omata T et al. New neurons use Slit-Robo signaling to migrate through the glial meshwork and approach a lesion for functional regeneration. Science advances. 2018; 4: eaav0618。

74. Dominici C, Rappeneau Q, Zelina P, Fouquet S, Chédotal A. Non-cell autonomous control of precerebellar neuron migration by Slit and Robo proteins. Development. 2018; 145: dev.150375.

75. Chen Z, Gore BB, Long H, Ma L, Tessier-Lavigne M. Alternative splicing of the Robo3 axon guidance receptor governs the midline switch from attraction to repulsion. Neuron. 2008; 58: 325-32.

76. Wang B, Xiao Y, Ding BB, Zhang N, Yuan X, Gui L, et al. Induction of tumor angiogenesis by Slit-Robo signaling and inhibition of cancer growth by blocking Robo activity. Cancer Cell. 2003; 4: 19-29.

77. Rama N, Dubrac A, Mathivet T, Ni-Charthaigh RA, Genet G, Cristofaro B, et al. Slit2 signaling through Robo1 and Robo2 is required for retinal neovascularization. Nat Med. 2015; 21: 483-91.

78. Li S, Huang L, Sun Y, Bai Y, Yang F, Yu W, et al. Slit2 promotes angiogenic activity via the Robo1-VEGFR2-ERK1/2 pathway in both in vivo and in vitro studies. Invest Ophthalmol Vis Sci. 2015; 56: 5210-7.

79. Guo SW, Zheng Y, Lu Y, Liu X, Geng JG. Slit2 overexpression results in increased microvessel density and lesion size in mice with induced endometriosis. Reprod Sci. 2013; 20: 285-98.

80. Nieminen T, Toivanen PI, Laakkonen JP, Heikura T, Kaikkonen MU, Airenne $\mathrm{KJ}$, et al. Slit2 modifies VEGF-induced angiogenic responses in rabbit skeletal muscle via reduced eNOS activity. Cardiovasc Res. 2015; 107: 267-76.

81. Marlow R, Binnewies M, Sorensen LK, Monica SD, Strickland P, Forsberg EC, et al. Vascular Robo4 restricts proangiogenic VEGF signaling in breast. Proc Natl Acad Sci U S A. 2010; 107: 10520-5.

82. Zhao H, Ahirwar DK, Oghumu S, Wilkie T, Powell CA, Nasser MW, et al. Endothelial Robo4 suppresses breast cancer growth and metastasis through regulation of tumor angiogenesis. Mol Oncol. 2016; 10: 272-81.

83. Romano E, Manetti M, Rosa I, Fioretto BS, Ibba-Manneschi L, Matucci-Cerinic $\mathrm{M}$ et al. Slit2/Robo4 axis may contribute to endothelial cell dysfunction and angiogenesis disturbance in systemic sclerosis. Annals of the Rheumatic Diseases. 2018; 77: 1665-1674.

84. Enomoto S, Mitsui K, Kawamura T, Iwanari H, Daigo K, Horiuchi K, et al. Suppression of Slit2/Robo1 mediated HUVEC migration by Robo4. Biochem Biophys Res Commun. 2016; 469: 797-802.

85. Dunaway CM, Hwang Y, Lindsley CW, Cook RS, Wu JY, Boothby M, et al. Cooperative signaling between Slit2 and Ephrin-A1 regulates a balance between angiogenesis and angiostasis. Mol Cell Biol. 2011; 31: 404-16.

86. Zhang B, Dietrich UM, Geng JG, Bicknell R, Esko JD, Wang L. Repulsive axon guidance molecule Slit3 is a novel angiogenic factor. Blood. 2009; 114: 4300-9.

87. Jones CA, Nishiya N, London NR, Zhu W, Sorensen LK, Chan AC, et al. Slit2-Robo4 signalling promotes vascular stability by blocking Arf6 activity. Nat Cell Biol. 2009; 11: 1325-31.

88. Wu JY, Feng L, Park HT, Havlioglu N, Wen L, Tang H, et al. The neuronal repellent Slit inhibits leukocyte chemotaxis induced by chemotactic factors. Nature. 2001; 410: 948-52

89. Tole S, Mukovozov IM, Huang YW, Magalhaes MA, Yan M, Crow MR, et al. The axonal repellent, Slit2, inhibits directional migration of circulating neutrophils. J Leukoc Biol. 2009; 86: 1403-15.

90. Chaturvedi S, Yuen DA, Bajwa A, Huang YW, Sokollik C, Huang L, et al. Slit2 prevents neutrophil recruitment and renal ischemia-reperfusion injury. J Am Soc Nephrol. 2013; 24: 1274-87.

91. Altay T, McLaughlin B, Wu JY, Park TS, Gidday JM. Slit modulates cerebrovascular inflammation and mediates neuroprotection against global cerebral ischemia. Exp Neurol. 2007; 207: 186-94. 
92. Kanellis J, Garcia GE, Li P, Parra G, Wilson CB, Rao Y, et al. Modulation of inflammation by slit protein in vivo in experimental crescentic glomerulonephritis. Am J Pathol. 2004; 165: 341-52.

93. Guan H, Zu G, Xie Y, Tang H, Johnson M, Xu X, et al. Neuronal repellent Slit2 inhibits dendritic cell migration and the development of immune responses. J Immunol. 2003; 171: 6519-26.

94. London NR, Zhu W, Bozza FA, Smith MC, Greif DM, Sorensen LK, et al. Targeting Robo4-dependent Slit signaling to survive the cytokine storm in sepsis and influenza. Sci Transl Med. 2010; 2: 23ra19.

95. Pilling D, Chinea LE, Consalvo KM, Gomer RH. Different Isoforms of the Neuronal Guidance Molecule Slit2 Directly Cause Chemoattraction or Chemorepulsion of Human Neutrophils. J Immunol. 2019; 202: 239-248.

96. Sharma G, Mirza S, Prasad CP, Srivastava A, Gupta SD, Ralhan R. Promoter hypermethylation of p16INK4A, p14ARF, CyclinD2 and Slit2 in serum and tumor DNA from breast cancer patients. Life Sci. 2007; 80: 1873-81.

97. Tseng RC, Lee SH, Hsu HS, Chen BH, Tsai WC, Tzao C, et al. SLIT2 attenuation during lung cancer progression deregulates beta-catenin and E-cadherin and associates with poor prognosis. Cancer Res. 2010; 70: 543-51.

98. Jin J, You H, Yu B, Deng Y, Tang N, Yao G, et al. Epigenetic inactivation of SLIT2 in human hepatocellular carcinomas. Biochem Biophys Res Commun. 2009; 379: 86-91.

99. Dickinson RE, Dallol A, Bieche I, Krex D, Morton D, Maher ER, et al. Epigenetic inactivation of SLIT3 and SLIT1 genes in human cancers. Br J Cancer. 2004; 91: 2071-8.

100. Shi R, Liu W, Liu B, Xu Z, Chen L, Zhang Z. Slit2 expression and its correlation with subcellular localization of beta-catenin in gastric cancer. Oncol Rep. 2013; 30: $1883-9$.

101. Ao JY, Chai ZT, Zhang YY, Zhu XD, Kong LQ, Zhang N, et al. Robo1 promotes angiogenesis in hepatocellular carcinoma through the Rho family of guanosine triphosphatases' signaling pathway. Tumour Biol. 2015; 36: 8413-24.

102. Prasad A, Paruchuri V, Preet A, Latif F, Ganju RK. Slit-2 induces a tumor-suppressive effect by regulating beta-catenin in breast cancer cells. J Biol Chem. 2008; 283: 26624-33.

103. Vaughen J, Igaki T. Slit-Robo repulsive signaling extrudes tumorigenic cells from epithelia. Dev Cell. 2016; 39: 683-95.

104. Yuan M, Guo H, Li J, Sui C, Qin Y, Wang J et al. Slit2 and Robo1 induce opposing effects on metastasis of hepatocellular carcinoma Sk-hep-1 cells. Int J Oncol. 2016; 49: 305-15.

105. Denk AE, Braig S, Schubert T, Bosserhoff AK. Slit3 inhibits activator protein 1-mediated migration of malignant melanoma cells. Int J Mol Med. 2011; 28: 721-6.

106. Shi RL, Qu N, Liao T, Wang YL, Wang Y, Sun GH, et al. Expression, clinical significance and mechanism of Slit2 in papillary thyroid cancer. Int J Oncol. 2016; 48: 2055-62.

107. Jeon MJ, Lim S, You MH, Park Y, Song DE, Sim S, et al. The role of Slit2 as a tumor suppressor in thyroid cancer. Molecular and Cellular Endocrinology. 2019; 483: 87-96

108. Prasad A, Fernandis AZ, Rao Y, Ganju RK. Slit protein-mediated inhibition of CXCR4-induced chemotactic and chemoinvasive signaling pathways in breast cancer cells. J Biol Chem. 2004; 279: 9115-24.

109. Schmid BC, Rezniczek GA, Fabjani G, Yoneda T, Leodolter S, Zeillinger R. The neuronal guidance cue Slit2 induces targeted migration and may play a role in brain metastasis of breast cancer cells. Breast Cancer Res Treat. 2007; 106. 333-42.

110. Qin F, Zhang H, Ma L, Liu X, Dai K, Li W, et al. Low expression of Slit2 and Robo1 is associated with poor prognosis and brain-specific metastasis of breast cancer patients. Sci Rep. 2015; 5: 14430.

111. Yu J, Zhang X, Kuzontkoski PM, Jiang S, Zhu W, Li DY, et al. Slit2N and Robo4 regulate lymphangiogenesis through the VEGF-C/VEGFR-3 pathway. Cell Commun Signal. 2014; 12: 25.

112. Gohrig A, Detjen KM, Hilfenhaus G, Korner JL, Welzel M, Arsenic R, et al. Axon guidance factor SLIT2 inhibits neural invasion and metastasis in pancreatic cancer. Cancer Res. 2014; 74: 1529-40.

113. Fujiwara K, Koyama K, Suga K, Ikemura M, Saito Y, Hino A, et al. 90Y-labeled anti-ROBO1 monoclonal antibody exhibits antitumor activity against small cell lung cancer xenografts. PLoS One. 2015; 10: e0125468.

114. Fujiwara K, Koyama K, Suga K, Ikemura M, Saito Y, Hino A, et al. A (90)Y-labelled anti-ROBO1 monoclonal antibody exhibits antitumour activity against hepatocellular carcinoma xenografts during ROBO1-targeted radioimmunotherapy. EJNMMI Res. 2014; 4: 29.

115. Han X, Zhang MC. Potential anti-angiogenic role of Slit2 in corneal neovascularization. Exp Eye Res. 2010; 90: 742-9.

\section{Author Biography}

Dr. Daiming Fan is a Professor and Director of Xijing Hospital of Digestive Diseases, Fourth Military Medical University. He is also a Member of Chinese Academy of Engineering and Foreign Associate of National Academy of Medicine, USA. At present, he acts as President of China Anti-Cancer Association and President of Asia Pacific Association of Digestive Disease. The current research interests in professor Fan's group include: (1) mechanism of drug resistance in cancer; (2) systematic biologic research in cancer; (3) diagnostic and predictive marker for cancer. 